\title{
Self-assembly of polyelectrolyte multilayer pervaporation membranes by a dynamic layer-by-layer technique on a hydrolyzed polyacrylonitrile ultrafiltration membrane
}

\author{
Guojun Zhang ${ }^{\text {a }}$, Haihong Yan ${ }^{\mathrm{a}}$, Shulan $\mathrm{Ji}^{\mathrm{a}, *}$, Zhongzhou Liu ${ }^{\mathrm{b}}$ \\ ${ }^{a}$ Center for Membrane Technology, College of Environmental and Energy Engineering, Beijing University of Technology, Beijing 100022, PR China \\ ${ }^{\mathrm{b}}$ Research Center for Eco-Environmental Sciences, Chinese Academy of Sciences, Beijing 100085, PR China
}

Received 20 July 2006; received in revised form 13 November 2006; accepted 16 November 2006

Available online 23 November 2006

\begin{abstract}
This paper is concerned with the self-assembly of polyelectrolyte multilayer membranes (PEMMs) by using dynamic layer-by-layer (LBL) adsorption technique for pervaporation separation of water/alcohol mixtures. The polyacrylonitrile (PAN) ultrafiltration membrane used as a support was firstly hydrolyzed with alkaline solutions followed by alternatively depositing polyethyleneimine (PEI) and polyacrylic acid (PAA) under a pressure of $0.1 \mathrm{MPa}$. The PEI-ethanol solution and PEI-aqueous solution were used to investigate the effects of solvents on the assembly process. It was found that both separation factor and permeate flux were improved remarkably by replacing PEI aqueous solution with PEI-ethanol solution. Because only a few composite bilayers were needed to achieve a good capability in the dynamic LBL process, the hydrolysis degrees of PAN support membrane would strongly affect the pervaporation membrane performances. It was also noted that the exposure of membranes to low $\mathrm{pH}$ after hydrolysis would not benefit for the assembly. Further studies were conducted to investigate the effects of alkali species on the PAN hydrolysis and pervaporation performances of PEMMs. The contribution of alkali species on the pervaporation performance was in the order of $\mathrm{KOH}>\mathrm{NaOH}>\mathrm{LiOH}$. Finally, the performances of PEI/PAA multilayer membranes assembled on the hydrolyzed PAN support were evaluated with a relatively wide range of feed temperature and concentration. The PEMMs obtained with only 2.5 bilayers had a separation factor of 604 and a permeate flux of $314 \mathrm{~g} / \mathrm{m}^{2} \mathrm{~h}\left(70^{\circ} \mathrm{C}\right)$ for pervaporation of $95 \mathrm{wt} \%$ ethanol-water mixture.
\end{abstract}

(C) 2007 Elsevier B.V. All rights reserved.

Keywords: Polyelectrolyte multilayer membranes (PEMMs); Dynamic layer-by-layer process; Hydrolysis; Polyacrylonitrile (PAN); Pervaporation; Water/alcohol mixture

\section{Introduction}

Pervaporation is a promising, membrane-based technique for the separation of liquid mixtures [1]. Synthesis of novel membranes with good separation capability is still a major research goal in pervaporation science [2]. Recently, self-assembled ultrathin films have received considerable interest and could also be used to prepare pervaporation membranes. The layer-bylayer (LBL) adsorption of oppositely charged polyelectrolytes provides a particularly versatile method to form a polyelectrolyte self-assembled membrane whose thickness can be controlled in the nanometer range. A majority of studies have extensively

\footnotetext{
* Corresponding author. Tel.: +86 1067392961 ; fax: +86 1067391983. E-mail address: jshl@bjut.edu.cn (S. Ji).
}

investigated the molecular structure of polyelectrolytes, molecular weight of polyelectrolytes, number of deposited layer pairs, $\mathrm{pH}$ value, ionic strength and various other factors influencing the multilayer growth and pervaporationn performances [2-7]. The studies of Tieke et al. [2-7] showed that a significantly large number of depositions of anionic/cationic polyelectrolytes are needed in order to achieve a high selectivity. It was noted that as many as 60 bilayers had to be deposited to obtain membranes with sufficient properties in LBL adsorption process. In view of the fact that LBL is a time-consuming process, great efforts have also been made in developing new methods to reduce the number of deposition cycles required. For example, Sullivan and Bruening [8] combined the versatility of LBL adsorption with covalent interlayer cross-linking to assemble ultrathin polyimide pervaporation membranes. The most promising membranes obtained with 12.5 bilayers give a remarkable 
water-isopropanol selectivity of 6100 along with a flux of $2 \mathrm{~kg} \mathrm{~m}^{-2} \mathrm{~h}^{-1}$ for pervaporation of $90 \%$ isopropanol at $50{ }^{\circ} \mathrm{C}$. Zhu et al. [9] proposed to reduce the deposition cycles by using a relatively dilute concentration of the polyelectrolytes in the first few cycles followed by depositions with more concentrated polyelectrolyte solutions. They also proposed to use a singlesided coating method to improve the membrane permeability. It was demonstrated by Zhu's study that a good permselectivity could be achieved with less than 10 cycles of deposition. We have reported [10] recently on the dynamic LBL adsorption technique, which would allow reduction of the deposition cycles.

As above mentioned, the traditional single LBL adsorption involved relatively long periods in order to obtain defect-free pervaporation membrane. The effects of support membrane properties on pervaporation performance were usually neglectable during the formation of 50-60 bilayers required on the support. Thus, few works have dealt with the investigations of support membrane properties during the self-assembly of polyelectrlyte membrane by LBL adsorption. However, in the above-mentioned recently developed self-assembly methods, especially for dynamic LBL process, only a few polylectrolyte pairs were deposited on the support membrane. In these cases, it is necessary to understand the effects of the support membrane properties on the multilayer growth of polyelectrolyte self-assembly systems.

In our previous study [10], the PAA/PEI pairs were alternatively deposited on the polyethersulfone (PES) support membrane under a certain pressure. The PES support membranes have good mechanical and chemical properties but do not have any functional groups on their surfaces, which can form ionic bonds with the polyelectrolyte pairs. Consequently, there are no such strong interactions as ionic bonds between the support membrane and the polyelectrolyte pairs deposited. Basically, in order to obtain long-term stability of self-assembled pervaporation membrane, the support membranes should be treated by chemical/physical methods to achieve negative or positive charges before deposition. Tieke's group has usually used oxygen plasma to treat the support membranes such as PAN/PET (a polyethyleneterephthalate fleece coated with a thin layer of polyacrylonitrile) [2-7]. Zhu et al. selected the polyacrylonitrile (PAN) ultrafiltration membrane hydrolyzed with sodium hydroxide as the support membrane. This is based on the conversion of $-\mathrm{CN}$ groups on the PAN membrane surface into carboxyl groups. After hydrolysis, the carboxyl groups can be used to adsorb the polycations by electrostatic force. Thus, the LBL adsorption could be proceeded in a serial sequences. Although there is increasing application of PAN ultrafiltration (UF) membranes as the support membrane, the effects of hydrolysis degree on the pervaporation performance of polyelectrolyte membrane remains unknown.

Another key problem regarding polyelectolyte multilayer pervaporation membranes is swelling of hydrophilic materials during the assembly process. The membranes with high water-pervaporation selectivities generally contain hydrophilic materials that preferentially absorb water [8]. Based on our previous study [10], we understand that the dramatic swelling would lead to the miscellaneous structural order between the polycations and polyanion, which would not benefit for the pervaporation membrane with good capability. Hence, it's important to avoid the swelling of polyelectrolyte materials during the assembly process.

In this paper, dynamic layer-by-layer technique was used to assemble the polyelectrolyte multilayer pervaporation membranes. Different from the previous study, the PAN ultrafiltration membrane used as the support was firstly hydrolyzed with alkaline solutions followed by alternatively depositing polyethyleneimine (PEI) and polyacrylic acid (PAA) under a pressure of $0.1 \mathrm{MPa}$. The purpose is to investigate the effects of support membrane properties on the pervaporation performance of polyelectrolyte membrane with a few pairs. Meanwhile, it was also expected to avoid the swelling during the assembly process. This could be obtained by using the alcohol to dissolve PEI rather than de-ionized water. The effects of hydrolysis degree, different hydrolysis solutions, the $\mathrm{HCl}$ treatment and the solvents of polycations on membrane performance were investigated. The pervaporation measurements were also carried out under the different operating conditions by changing feed temperature and water content in the feed solutions.

\section{Experimental}

\subsection{Materials}

Lithium hydroxide, sodium hydroxide and potassium hydroxide used in the hydrolysis study of polyacrylonitrile (PAN) ultrafiltration membranes were of analytical grade. The PAA powder having average molecular weight of 4,000,000 and cytochrome $\mathrm{C}$ (CytC) with the molecular weight of 12,384 was obtained from Aldrich. Linear poly(ethyleneimine) (PEI) with the molecular weight of 60,000 was purchased from ACROS. The ethanol used as solvents for PEI were provided by Beijing Chemical Factory. Poly(ethylene glycol) (PEG) having the molecular weight of 6000 was also supplied by Beijing Chemical Factory. The flat-sheet PAN UF membrane used as a support layer was provided by the Research Center for EcoEnvironmental Sciences, Chinese Academy of Sciences. The molecular weight cut-off of the support UF membrane was 20,000 .

\subsection{Hydrolysis of PAN UF membrane}

The PAN UF membrane with an effective membrane area of $32 \mathrm{~cm}^{2}$ was hydrolyzed by immersing into the aqueous solutions of lithium hydroxide, sodium hydroxide and potassium hydroxide, respectively. The hydrolysis tests were conducted in a water bath so that temperature can be manipulated to predetermined levels. After hydrolyzing for a pre-determined period, the membranes was taken out and rinsed with de-ionized water until the $\mathrm{pH}$ values of the rinsed water reached about 7.0.

\subsection{Polyelectrolyte multilayer membrane preparation by dynamic $L B L$ process}

As previously reported [10], the preparation of polyelectrolyte multilayer membranes was carried out by using a $50 \mathrm{ml}$ 
stirred dead-ended filtration cell with approximately $79 \mathrm{~cm}^{2}$ membrane area. Aqueous PAA solution were prepared by dissolving the polymer in distilled water completely and stirred until homogeneous. The PEI was dissolved into de-ionized water and ethanol, respectively, to prepare the homogeneous solutions. The hydrolyzed PAN UF membranes were loaded in a dead-ended filtration cell. The dynamic membrane was accomplished by filtrating the polyanion and polycation alternatively during a pre-determined period of filtration. The following steps were orderly carried out. (a) PEI solution was poured into the stirred cell and pressured under a pressure of $0.1 \mathrm{MPa}$ for a predetermined period. (b) The membrane was taken out, briefly rinsed with de-ionized water for approximately $5 \mathrm{~min}$ and dried in an oven at $50{ }^{\circ} \mathrm{C}$ for a pre-determined period. (c) PAA solution was poured into the stirred cell in which the dried membrane in (b) had been loaded, and was pressured through the membrane under a pressure of $0.1 \mathrm{MPa}$ by using a nitrogen cylinder. (d) The same way as (b). Steps (a)-(d) were repeated up to the pre-determined times. Upon the formation of polyelectrolyte multilayers membranes, they were stored for pervaporation experiments.

\subsection{Pervaporation experiments}

The membranes were characterized by the pervaporation of alcohol/water mixtures $(95: 5 \mathrm{~g} / \mathrm{g})$. The experimental apparatus and procedures for pervaporation have been described previously [10]. The membrane cell had an effective membrane area of $28.3 \mathrm{~cm}^{2}$. The permeate was condensed in liquid nitrogen traps. The experiments were carried out at a down-stream pressure of $100 \mathrm{~Pa}$ by vacuum pump. Fluxes were determined by measuring the weight of liquid collected in the cold traps during a certain time under steady-state conditions. The composition of the collected permeate was determined by gas chromatography (GC-14C, SHIMADZU). The separation factor was calculated from the quotient of the weight ratio of water and alcohol in the permeate, $Y_{\mathrm{HOH}} / Y_{\mathrm{ROH}}$, and in the feed, $X_{\mathrm{HOH}} / X_{\mathrm{ROH}}$ :

$\alpha=\frac{Y_{\mathrm{HOH}} / Y_{\mathrm{ROH}}}{X_{\mathrm{HOH}} / Y_{\mathrm{ROH}}}$

\subsection{Characterization techniques}

The CytC concentrations spectra were measured on a UV-2550 UV-vis spectrophotometer (SHIMADZU) at the wavelength of $280 \mathrm{~nm}$. A total organic carbon (TOC) analyzer (TOC-V $\mathrm{V}_{\mathrm{CPH}}$, SHIMADZU) was used to determine the TOC values of PEG solutions before and after ultrafiltration. Static water contact angle measurements were also performed using a JJC-1 contact angle analyzer (The Fifth Optical Instrument Factory, Changchun, PR China). Attenuated total reflectance FTIR spectra were obtained using a Vertex-70 spectrophotometer (Bruker, Germany).

\section{Results and discussion}

\subsection{Characterization of hydrolyzed PAN UF membrane}

It's well known that the hydrolysis of PAN membranes was influenced by the alkaline concentration, hydrolysis time and hydrolysis temperature. Thus, the effects of these conditions were investigated in the previous study [11] to establish suitable hydrolysis conditions based on the pure flux decline and the retention of CytC and PEG. In relation to sodium hydroxide solution, a suitable condition of $2 \mathrm{~N} \mathrm{NaOH}$ at $60-70^{\circ} \mathrm{C}$ for a period of $60 \mathrm{~min}$ was determined. Given these conditions, the performance of hydrolyzed PAN UF membrane was summarized in Table 1.

It was noted from Table 1 that the membrane flux declined while the retention increased sharply after a relatively sufficient hydrolysis. This suggested the hydrolyzed PAN UF membrane became more compact compared to the PAN UF membrane without hydrolysis. Meanwhile, the formation of a polyelectrolyte layer (carboxylic acid salts) which swells more readily in water than the virgin membrane may also lead to the flux declination and retention enhancement. Infrared spectra of PAN membrane before and after hydrolysis are shown in Fig. 1. The characteristic peaks at $1733 \mathrm{~cm}^{-1}$ are attributed to the $-\mathrm{C}=\mathrm{O}$ stretching vibration. This is because the parent PAN UF membrane is a copolymer of polyacrylonitrile (PAN) and poly (methyl acrylate) (PMA). The peak completely vanished after hydrolysis. The spectrum of the PAN membrane before hydrolysis (Fig. 1(a)) contained the shoulders at 2243 and $1451 \mathrm{~cm}^{-1}$, which were due to the $-\mathrm{CN}$ group. As expected, the intensities of $-\mathrm{CN}$ group shoulder decreased sharply after hydrolysis. Taken together, the bands at 1568 and $1405 \mathrm{~cm}^{-1}$ in the spectra of hydrolyzed PAN membrane (Fig. 1(b)) provided strong evidence that carboxyl groups occurred primarily via hydrolysis of sodium hydroxide. Attenuated total reflectance FTIR spectroscopy in Fig. 1 further confirmed that most $-\mathrm{CN}$ groups on the PAN membrane surface were converted into carboxyl groups. Accordingly, the hydrophilicity of PAN membrane improved after hydrolysis since the surface contact angle decreased from $60^{\circ}$ to $29^{\circ}$ (Table 1). Obviously, the formation of carboxyl groups would benefit for the subsequent assembly of polyelectrolyte pairs due to its high charge density.

Table 1

The performances of PAN support membrane before and after hydrolysis

\begin{tabular}{|c|c|c|c|c|}
\hline Parameters & Pure water flux $\left(\mathrm{L} / \mathrm{m}^{2} \mathrm{~h}\right)$ & Rejection ratio of CytC (\%) & Rejection ratio of PEG $6000(\%)$ & Contact angle $\left({ }^{\circ}\right)$ \\
\hline Before hydrolysis & 201.3 & 10.02 & 0.84 & 60 \\
\hline After hydrolysis & 6.8 & 98.87 & 93.07 & 29 \\
\hline
\end{tabular}

Hydrolysis conditions: $2 \mathrm{~N} \mathrm{NaOH}$, hydrolysis temperature: $65^{\circ} \mathrm{C}$, hydrolysis time: $60 \mathrm{~min}$. 

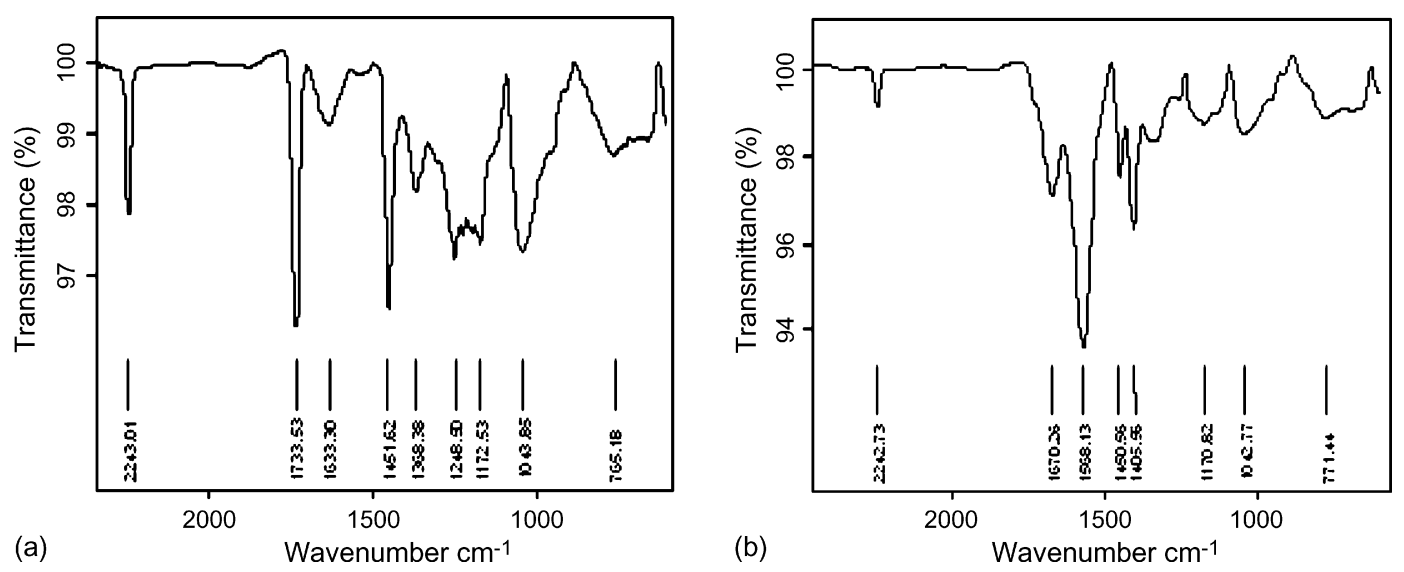

Fig. 1. IR spectra of PAN UF membrane before and after hydrolysis, (a) IR spectrum of PAN UF membrane before hydrolysis, (b) IR spectrum of PAN UF membrane after hydrolysis, hydrolysis conditions: $2 \mathrm{~N} \mathrm{NaOH}$, hydrolysis temperature $65^{\circ} \mathrm{C}$ hydrolysis time $1 \mathrm{~h}$.

\subsection{Effect of PEI solutions}

In the past studies, the swelling of pervaporation membrane in the operation has received considerable attentions by many researchers [8,12-15]. However, relatively few works have dealt with the swelling of polyelectrolytes themselves during the assembly of PEMMs. We have recently reported that [10] exceeding contact between PAA and PEI aqueous solution may result in the swelling of PAA during the LBL process and in turn the decline of separation factor of the membrane obtained. In this work attempts were made to substantially reduce the swelling while still retaining a good permselectivity. To do this, PEI-ethanol solution was proposed to replace PEI aqueous solution during the assembly process of PEMMs. Table 2 shows the effects of PEI solutions on the pervaporation performance.

The results (Table 2) indicated that both separation factor and permeate flux obtained from PEI-ethanol solution were much higher than those associated with PEI aqueous solution. This possibly was due to the swelling differences of PAA layer while using the two solvents. In order to investigate the swelling degree of PAA in the two solvents, $0.05 \mathrm{~g}$ PAA was added into $25 \mathrm{ml}$ solvents. It was observed that PAA was much more easily to dissolve in de-ionized water than in ethanol. In the dynamic LBL assembly of PEI/PAA pairs, the PAA framework was formed after deposition and drying steps. If the PAA layer deposited contacted with PEI aqueous solution for a period, some PAA would swell severely and in turn lead to the increase of membrane thickness. Subsequently, the permeate flux declined. Meanwhile, the interface regularity between PAA and PEI lay- ers might be influenced by swelling, which would result in lower separation factor. In the case of PEI-ethanol solutions, the swelling of PAA layer was much lower, which would benefit for both reduction of membrane thickness and keeping the interface regularity between PAA and PEI layers. Therefore, both separation factor and permeate flux were kept at a relatively high value.

\subsection{Effect of PAN hydrolysis degree}

In order to investigate the contribution of PAN hydrolysis degree on polyelectrolyte pervaporation membrane performance, the pervaporation performances of PEMMs assembled on the PAN UF membranes under different hydrolysis conditions were compared. Table 3 shows the variation of pervaporation performance with the different hydrolysis conditions. Do note only one PEI layer ( 0.5 bilayer) was deposited on the hydrolyzed PAN support so as to clearly observe the effects of PAN hydrolysis degree.

It was clearly noted that the pervaporation performances of the PEMMs were strongly dependent on the hydrolysis degree of PAN support. Particularly, the integrity and regularity of the first polyion layer was influenced by the charge density of the support. When increasing the hydrolysis temperature, improving alkaline concentration or prolonging the hydrolysis time, more and more $-\mathrm{CN}$ groups on the polyacrylonitrile membrane surface and pore will be converted into carboxyl groups. The more - $\mathrm{COO}$ - groups converted, the more compact PEI layer formed on the hydrolyzed PAN support. However, in view of the fact

Table 2

Effects of the PEI solution on pervaporation performances of PEMMs

\begin{tabular}{lllcc}
\hline PEI solution & EtOH content in feed solution $(\%)$ & Water content in permeate $(\%)$ & Permeate flux, $J\left(\mathrm{~g} / \mathrm{m}^{2} \mathrm{~h}\right)$ & Separation factor, $\alpha$ \\
\hline PEI aqueous solution $(0.25 \mathrm{wt} \%)$ & 95 & 93.81 & 92 & 288 \\
PEI-ethanol solution $(0.25 \mathrm{wt} \%)$ & 95 & 95.51 & 226 & 404
\end{tabular}

Hydrolysis conditions for PAN support membrane: $2 \mathrm{~N} \mathrm{NaOH}$, hydrolysis temperature: $65^{\circ} \mathrm{C}$, hydrolysis time: 60 min. Preparative conditions for PEMMs: 2.5 PEI/PAA bilayers, dynamic pressure: $0.1 \mathrm{MPa}, 20 \mathrm{~min}$ filtration time, $0.05 \mathrm{wt} \%$ PAA aqueous solution, $25^{\circ} \mathrm{C}$. Pervaporation conditions: feed temperature $40^{\circ} \mathrm{C}$, down-stream pressure $100 \mathrm{~Pa}$, EtOH content in feed solution $95 \mathrm{wt} \%$. 
Table 3

Effects of the hydrolysis degree on pervaporation performance of polyelectrolyte multilayer membranes

\begin{tabular}{|c|c|c|c|c|c|c|}
\hline $\begin{array}{l}\text { Experimental } \\
\text { number }\end{array}$ & $\begin{array}{l}\text { Hydrolysis } \\
\text { temperature }\left({ }^{\circ} \mathrm{C}\right)\end{array}$ & $\begin{array}{l}\mathrm{NaOH} \\
\text { concentration }\end{array}$ & $\begin{array}{l}\text { Hydrolysis time } \\
\text { (min) }\end{array}$ & $\begin{array}{l}\text { Water content in } \\
\text { permeate }(\%)\end{array}$ & $\begin{array}{l}\text { Permeate flux } \\
\left(\mathrm{g} / \mathrm{m}^{2} \mathrm{~h}\right)\end{array}$ & $\begin{array}{l}\text { Separation } \\
\text { factor } \alpha\end{array}$ \\
\hline 1 & 40 & $2 \mathrm{~N}$ & 60 & 10.33 & 9936 & 2 \\
\hline 2 & 50 & $2 \mathrm{~N}$ & 60 & 55.62 & 721 & 24 \\
\hline 3 & 65 & $2 \mathrm{~N}$ & 60 & 75.92 & 429 & 60 \\
\hline 4 & 65 & $1.5 \mathrm{~N}$ & 60 & 62.86 & 565 & 32 \\
\hline 5 & 65 & $2.5 \mathrm{~N}$ & 60 & 78.23 & 353 & 68 \\
\hline 6 & 65 & $3 N$ & 60 & 80.60 & 299 & 79 \\
\hline 7 & 65 & $2 \mathrm{~N}$ & 40 & 66.01 & 501 & 37 \\
\hline 8 & 65 & $2 \mathrm{~N}$ & 50 & 70.62 & 458 & 46 \\
\hline 9 & 65 & $2 \mathrm{~N}$ & 70 & 78.26 & 350 & 68 \\
\hline
\end{tabular}

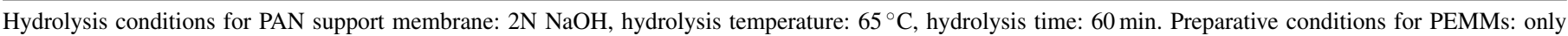

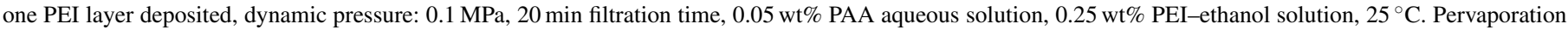
conditions: feed temperature $40^{\circ} \mathrm{C}$, down-stream pressure $100 \mathrm{~Pa}$, EtOH content in feed solution $95 \mathrm{wt} \%$.

that exceeding hydrolysis will reduce the mechanical strength of PAN membranes, the relatively mild hydrolysis conditions of $2 \mathrm{~N} \mathrm{NaOH}$ at $65^{\circ} \mathrm{C}$ for a period of $60 \mathrm{~min}$ were selected for the subsequent experiments.

\subsection{Effect of exposure of membranes to low $\mathrm{pH}$}

To investigate the effects of exposure to low $\mathrm{pH}$, the hydrolyzed PAN was soaked into $0.1 \mathrm{~N} \mathrm{HCl}$ for a period of $60 \mathrm{~min}$ and then assembled PEI/PAA pairs. The results are listed in Table 4.

The membranes associated with $\mathrm{HCl}$ treatment shows a quick decrease in both selectivity and permeate flux (Table 4). This is because the exposure of membranes to low $\mathrm{pH}$ controls the degree of ionization of the polar groups [2-7]. After $\mathrm{HCl}$ treatment, the more - COO-Na groups converted into the carboxyl acid, which would lead to the poor ionization of hydrolyzed PAN membranes and in turn to weaken the binding ability of PAN support. In that case, the regularity of PEEMs became much worse within only a few pairs deposited. A different layer structure might be formed while preparing the multilayer systems from different starting points.

\subsection{Effect of hydrolysis solutions}

In the past studies, sodium hydroxide was commonly used as hydrolysis agent for PAN membrane. The following exper- iments were intended to examine other alkaline solutions for hydrolysis of PAN membrane, i.e. lithium hydroxide and potassium hydroxide, and to observe if these alkali species would be beneficial for the subsequent polyelectrolyte multilayer assembly. Under the temperature of $65^{\circ} \mathrm{C}$, the PAN UF membranes were firstly hydrolyzed by $2 \mathrm{~N} \mathrm{LiOH}, 2 \mathrm{~N} \mathrm{NaOH}$ and $2 \mathrm{~N} \mathrm{KOH}$ for a period of $60 \mathrm{~min}$, respectively. The polyelectrolyte pairs were subsequently assembled on the hydrolyzed PAN membranes by dynamic LBL. In Fig. 2, flux and water content in the permeate are plotted versus the bilayer number of the various hydrolysis agents. In all cases, a preferential transport of water is observed.

It was noted from Fig. 2 that all the water contents in permeate increased with the increase in the deposition cycles. This is due to the enhanced hydrophilicity of separating layer with the growth of polyelectrolyte complex layer. Meanwhile, the defects such as very small pores in the substrates are covered by the polyelectrolyte complex layer [12]. Among the three alkaline hydrolysis agents, the water content in permeate obtained from $\mathrm{KOH}$ was much higher than those obtained from $\mathrm{NaOH}$ and $\mathrm{LiOH}$, especially for the initial two deposition cycles. For example, for 0.5 bilayer (only one PEI layer) deposited, the water content in permeate obtained from $\mathrm{KOH}$ was $85.13 \mathrm{wt} \%$ while those values obtained from $\mathrm{NaOH}$ and $\mathrm{LiOH}$ were 75.92 and $40.23 \mathrm{wt} \%$.

Further studies were conducted to eliminate the effects of alkali metals. The PAN UF membranes hydrolyzed with $2 \mathrm{~N}$

Table 4

Effects of exposure of membranes to low $\mathrm{pH}$ on pervaporation performance of PEMMs

\begin{tabular}{|c|c|c|c|c|c|}
\hline Bilayers number & $\begin{array}{l}\text { With or without } \\
\mathrm{HCl} \text { treatment }\end{array}$ & $\begin{array}{l}\text { EtOH content in } \\
\text { feed solution }(\%)\end{array}$ & $\begin{array}{l}\text { Water content in } \\
\text { permeate }(\%)\end{array}$ & $\begin{array}{l}\text { Permeate flux } \\
\left(\mathrm{g} / \mathrm{m}^{2} \mathrm{~h}\right)\end{array}$ & $\begin{array}{l}\text { Separation } \\
\text { factor, } \alpha\end{array}$ \\
\hline \multirow[t]{2}{*}{0.5} & Without & 95 & 75.92 & 429 & 60 \\
\hline & With & 95 & 59.34 & 191 & 28 \\
\hline \multirow[t]{2}{*}{2.5} & Without & 95 & 95.51 & 226 & 404 \\
\hline & With & 95 & 88.47 & 148 & 146 \\
\hline
\end{tabular}

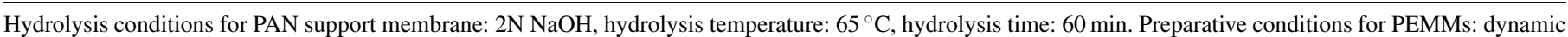

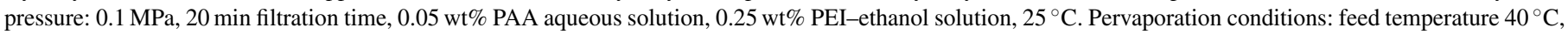
down-stream pressure $100 \mathrm{~Pa}, \mathrm{EtOH}$ content in feed solution $95 \mathrm{wt} \%$. 

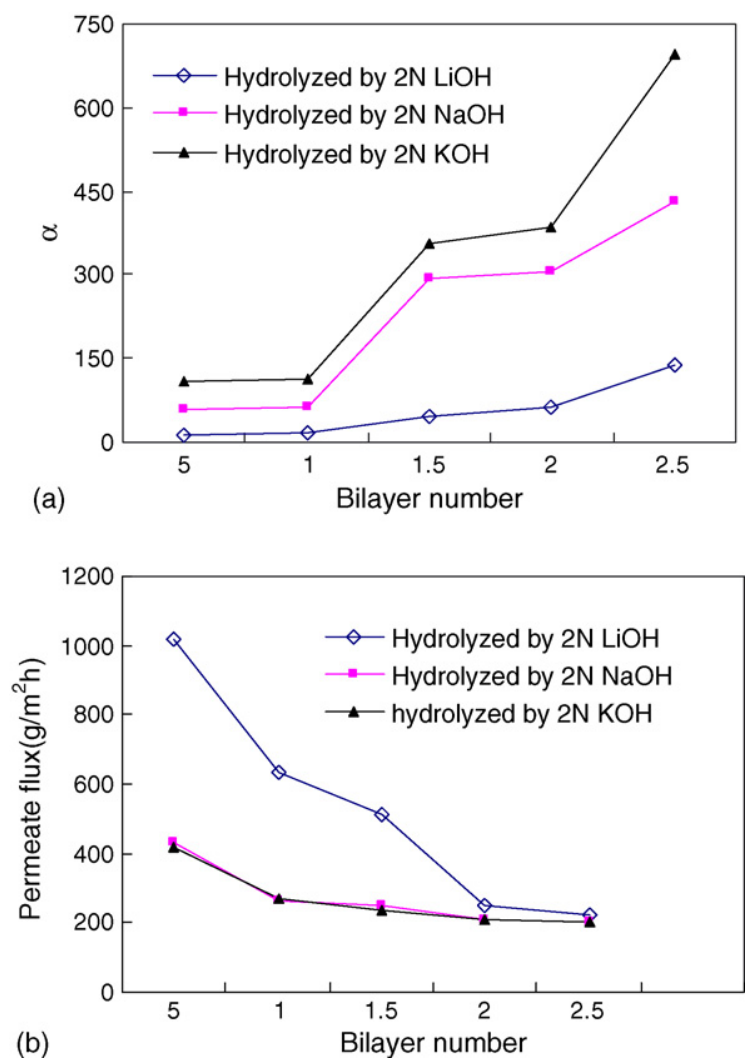

Fig. 2. Effects of alkali species on finial pervaporation performance of PEMMs, (a) Effects of alkali species on separation factor, (b) Effects of alkali species on permeate flux, (hydrolysis conditions for PAN support membrane: hydrolysis temperature: $65^{\circ} \mathrm{C}$, hydrolysis time: $60 \mathrm{~min}$, Preparative conditions: dynamic pressure: $0.1 \mathrm{MPa}, 20 \mathrm{~min}$ filtration time, $0.05 \mathrm{wt} \%$ PAA aqueous solution, $0.25 \mathrm{wt} \%$ PEI-ethanol solution, $25^{\circ} \mathrm{C}$. Pervaporation conditions: feed temperature $40^{\circ} \mathrm{C}$, down-stream pressure $100 \mathrm{~Pa}$, EtOH content in feed solution $95 \mathrm{wt} \%)$.

$\mathrm{LiOH}$ and $2 \mathrm{~N} \mathrm{KOH}$ were also immersed into $2 \mathrm{~N} \mathrm{NaCl}$ solutions to convert into-COONa support membrane before assembling PEI/PAA pairs. By using this method, it was thought that the single effects of hydrolysis degree could be investigated. The results in Fig. 3 indicated that even after conversion into-COONa, the selectivity of the membranes based on $\mathrm{KOH}$ hydrolysis became close to that obtained with $\mathrm{NaOH}$. The water content in permeate obtained from $\mathrm{LiOH}$ was still much lower than those obtained from $\mathrm{KOH}$ and $\mathrm{NaOH}$. These phenomena confirmed that the differences of hydrolysis degree caused by the different alkaline agents had a great influence on the finial separation performances of the PEMMs. The contribution of alkali species on the hydrolysis degree and pervaporation performance were orderly $\mathrm{KOH}>\mathrm{NaOH}>\mathrm{LiOH}$, which basically accorded with the order of basicity intensity. It was also noted that the effects of hydrolysis degree became less important with the growth of multilayer. For example, when PAN support were treated by $\mathrm{LiOH}-\mathrm{NaCl}, \mathrm{NaOH}, \mathrm{KOH}-\mathrm{NaCl}$, the water content in permeate associate with 2.5 bilayers were $92.698,95.728$ and $96.08 \mathrm{wt} \%$ while the fluxes were 213,200 , and $197 \mathrm{~g} / \mathrm{m}^{2} \mathrm{~h}$, respectively.
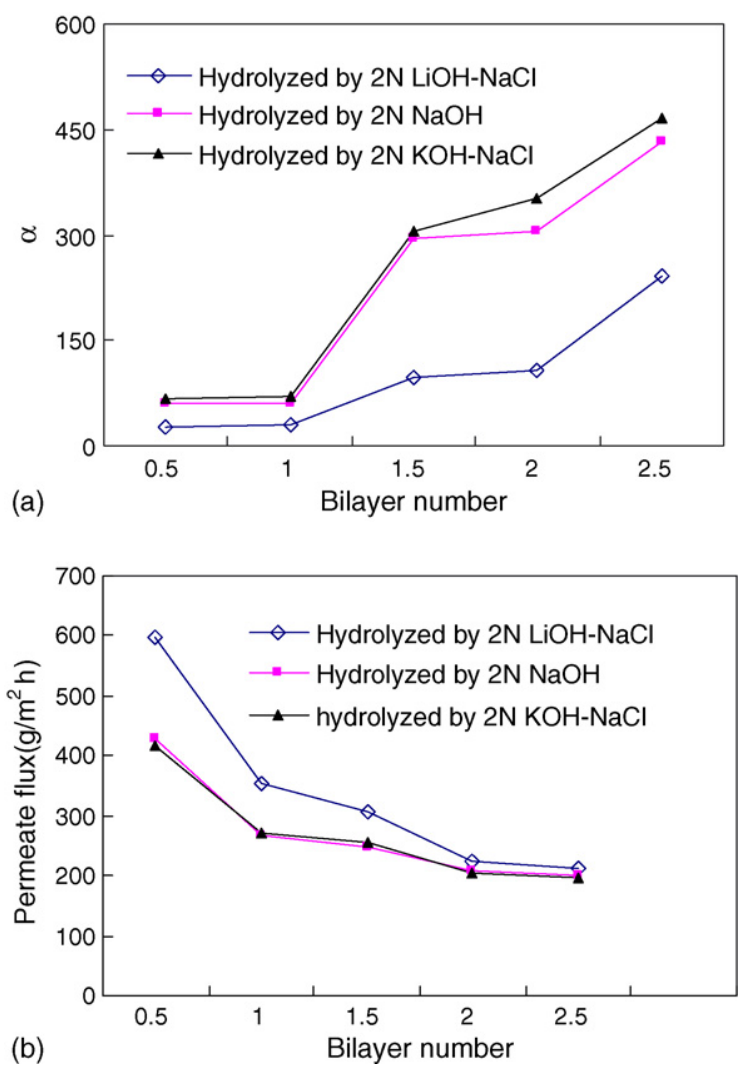

Fig. 3. Effects of $\mathrm{NaCl}$ treatment on pervaporation performance. (Hydrolysis conditions for PAN support membrane: hydrolysis temperature: $65^{\circ} \mathrm{C}$, hydrolysis time: $60 \mathrm{~min}$. Preparative conditions: dynamic pressure: $0.1 \mathrm{MPa}, 20 \mathrm{~min}$ filtration time, $0.05 \mathrm{wt} \%$ PAA aqueous solution, $0.25 \mathrm{wt} \%$ PEI-ethanol solution, $25^{\circ} \mathrm{C}$. Pervaporation conditions: feed temperature $40^{\circ} \mathrm{C}$, down-stream pressure $100 \mathrm{~Pa}, \mathrm{EtOH}$ content in feed solution $95 \mathrm{wt} \%$ ).

\subsection{Effects of feed temperature and water content in feed solution}

The PEMMs assembled by dynamic LBL on a hydrolyzed PAN UF membrane were evaluated within relatively wide ranges of feed temperature and water content in feed solution. As can be seen from Fig. 4(a), both permeate flux and water content in permeate increased with the increase in operating temperature. The increase in flux is due to the increases in the water vapor pressure of feed side and the diffusion coefficients. The variation of flux with feed temperature fit well for Arrhenius law $\left(J=J_{0} \exp \left(-E_{\mathrm{M}} / R T\right)\right)$ (Fig. 4(b)). The increase in selectivity was because the increase in diffusional selectivity of water was more significant than that of alcohol when increased feed temperature. Interestingly, different from our previous study [10], no peak value of selectivity was observed at the temperature of $40^{\circ} \mathrm{C}$. The possible reason was that the swellings of PAA and polyion complex near the hydrolyzed PAN membrane surface was much less than that near PES membrane surface, because the first complex pair was formed between $\mathrm{COO}^{-}$attached on PAN membrane surface and PEI. These phenomena could also be confirmed by calculating the water flux and alcohol flux, respectively. Fig. 5 proved that the water flux increased while the alcohol flux decreased with the increase in feed temperature. 

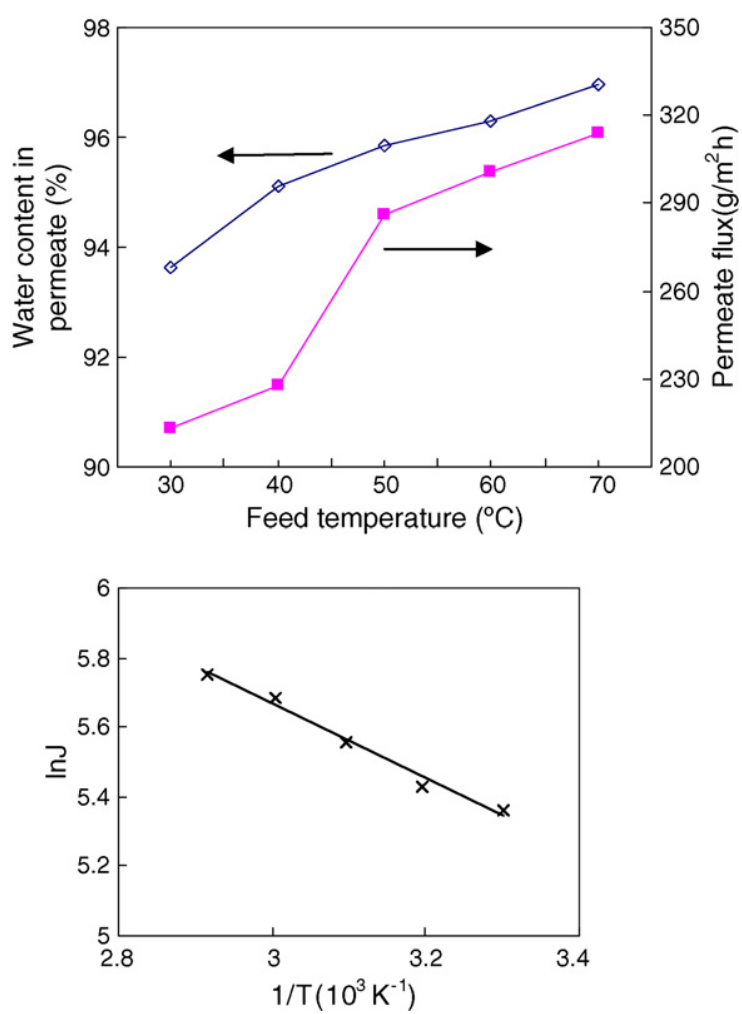

Fig. 4. Effect of feed temperature on pervaporation performance. (Hydrolysis conditions for PAN support membrane: $2 \mathrm{~N} \mathrm{NaOH}$, hydrolysis temperature: $65^{\circ} \mathrm{C}$, hydrolysis time: $60 \mathrm{~min}$. Preparative conditions for PEMMs: $2.5 \mathrm{PEI} / \mathrm{PAA}$ bilayers, dynamic pressure: $0.1 \mathrm{MPa}, 20 \mathrm{~min}$ filtration time, $0.05 \mathrm{wt} \%$ PAA aqueous solution, $0.25 \mathrm{wt} \%$ PEI-ethanol solution, $25^{\circ} \mathrm{C}$. Pervaporation conditions: feed temperature $40^{\circ} \mathrm{C}$, down-stream pressure $100 \mathrm{~Pa}$, EtOH content in feed solution $95 \mathrm{wt} \%)$.

Under the temperature of $70{ }^{\circ} \mathrm{C}$, the highest separation factor and permeate flux for pervaporation of $95 \mathrm{wt} \%$ water-ethanol mixture were 604 and $314 \mathrm{~g} / \mathrm{m}^{2}$ h, respectively. In Fig. 6, the water content in permeate are plotted versus the corresponding feed concentration. It was also noted that selectivity declined rapidly with increasing water content in feed solution while permeate flux increased. However, the permeate always contained a water content of more than $95 \mathrm{wt} . \%$.

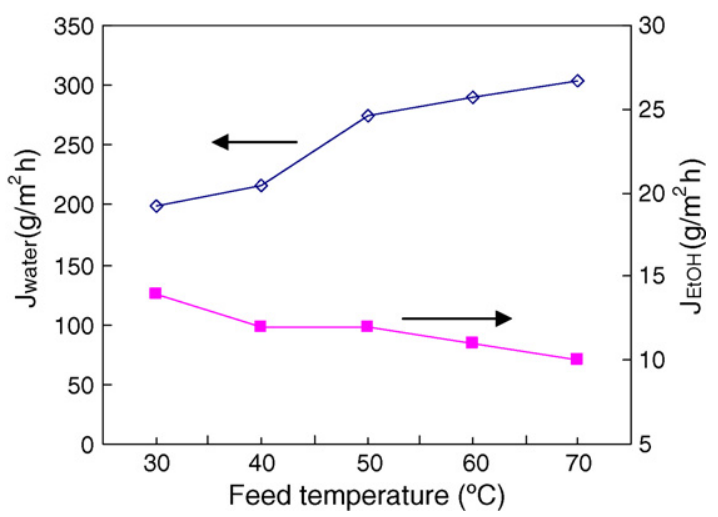

Fig. 5. Effects of feed temperature on water and alcohol fluxes. (Pervaporation conditions: down-stream pressure $100 \mathrm{~Pa}$, EtOH content in feed solution $95 \mathrm{wt} \%)$.

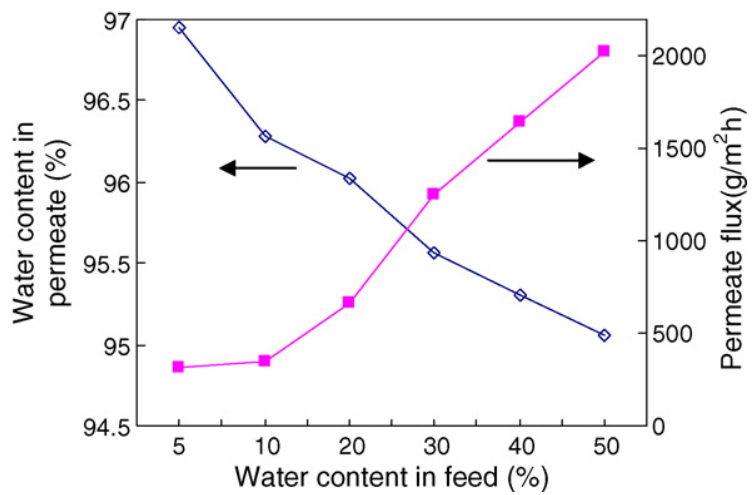

Fig. 6. Effect of water content in feed solution on pervaporation performance. (Pervaporation conditions: feed temperature $70^{\circ} \mathrm{C}$, down-stream pressure $100 \mathrm{~Pa})$.

\section{Conclusions}

In this study, the polyelectrolyte multilayer membranes for pervaporation separation of water/alcohol mixtures was self-assembled by alternatively depositing polyethyleneimine (PEI) and polyacrylic acid (PAA) on a hydrolyzed PAN support membrane. In order to avoid the swelling of PAA during the dynamic LBL process, PEI-ethanol solution was proposed to replace PEI aqueous solution. The experimental results suggested that both separation factor and permeate flux were improved remarkably. In addition, the effects of hydrolysis degrees of PAN support membrane were investigated. It was found that the PAN support membrane obtained from different hydrolysis conditions would strongly affect the pervaporation performances of PEMMs, especially for the initial 0.5 and 1.5 bilayers. With the growth of multilayer, the effects of support property would reduce. Because the dynamic LBL assembly only needs a few bilayers, it's important to screen the suitable hydrolysis conditions for the PAN support. In this work, the relatively mild hydrolysis conditions of $2 \mathrm{~N} \mathrm{NaOH}$ at $65^{\circ} \mathrm{C}$ for a period of $60 \mathrm{~min}$ were selected for the assembly of PEEMs. $\mathrm{HCl}$ treatment of the hydrolyzed PAN was found to be not beneficial for the assembly. Further researches suggested that the pervaporation performance varied with the alkali species for PAN hydrolysis. The contributions were in the order of $\mathrm{KOH}>\mathrm{NaOH}>\mathrm{LiOH}$. In addition, both permeate flux and water content in permeate increased as the operating temperature was raised. Under the temperature of $70^{\circ} \mathrm{C}$, the separation factor and the permeate flux of the PEMMs for pervaporation of $95 \mathrm{wt} \%$ ethanol-water mixture were about 604 and $314 \mathrm{~g} / \mathrm{m}^{2} \mathrm{~h}$, respectively. The water content in permeate could be maintained above $95.0 \%$ even the water content increased to $50 \%$ in feed solution.

\section{Acknowledgements}

This work was supported by the National Basic Research Program of China (No. 2003CB615701), the Beijing NOVA Programme (No. 2006B13), the Special Funding Project of the Beijing Municipal Commission of Education, PR China (No. 05005999200601) and the Start-up funds for $\mathrm{PhD}$ 
holders, Beijing University of Technology (127(VA)-00173, 52005013200501).

\section{References}

[1] B. Smitha, D. Suhanya, S. Sridhar, M. Ramakrishna, Separation of organic-organic mixtures by pervaporation: a review, J. Membr. Sci. 241 (2004) 1-21.

[2] L. Krasemann, A. Toutianoush, B. Tieke, Self-assembled polyelectrolyte multilayer membranes with highly improved pervaporation separation of ethanol/water mixtures, J. Membr. Sci. 181 (2001) 221-228.

[3] A. Toutianoush, B. Tieke, Pervaporation separation of alcohol/water mixtures using self-assembled polyelectrolyte multilayer membranes of high charge density, Mater Sci. Eng., C 22 (2002) 459-463.

[4] A. Toutianoush, L. Krasemann, B. Tieke, Polyelectrolyte multilayer membranes for pervaporation separation of alcohol/water mixtures, Colloids Surf. A 198-200 (2002) 881-889.

[5] F.V. Ackern, L. Krasemann, B. Tieke, Ultrathin membranes for gas separation and pervaporation prepared upon electrostatic self-assembly of polyelectrolytes, Thin Solid Films 327-329 (1998) 762-766.

[6] A. Toutianoush, B. Tieke, Selective transport and incorporation of highly charged metal and metal complex ions in self-assembled polyelectrolyte multilayer membranes, Mater. Sci. Eng. C 22 (2002) 135-139.

[7] R.V. Klitzing, B. Tieke, Polyelectrolyte membranes, Adv. Polym. Sci. 165 (2004) 177-210.
[8] D.M. Sullivan, M.L. Bruening, Ultrathin, cross-linked polyimide pervaporation membranes prepared from polyelectrolyte multilayers, J. Membr. Sci. 248 (2005) 161-170.

[9] Z. Zhu, X. Feng, A. Penlidis, Self-assembled nano-structured polyelectrolyte composite membranes for pervaporation, Mater. Sci. Eng., C 26 (2006) 1-8.

[10] G. Zhang, W. Gu, S. Ji, Z. Liu, Y. Peng, Z. Wang, Preparation of polyelectrolyte multilayer membranes by dynamic layer-by-layer process for pervaporation separation of alcohol/water mixtures, J. Membr. Sci. 280 (2006) 727-733.

[11] Haihong Yan, Guojun Zhang, Shulan Ji, Weiliang Gu, Zhongzhou Liu, Study on hydrolysis modification of polyacrylonitrile ultrafiltration membranes, Membr. Sci. Technol., in press (in Chinese).

[12] J. Meier-Haack, W. Lenk, D. Lehmann, K. Lunkwitz, Pervaporation separation of water/alcohol mixtures using composite membranes based on polyelectrolyte multilayer assemblies, J. Membr. Sci. 184 (2) (2001) 233-243.

[13] H. Karakane, M. Tsuyumoto, Y. Maeda, Z. Honda, Separation of water-ethanol by pervaporation through polyion complex composite membrane, J. Appl. Polym. Sci. 42 (1991) 3239-3299.

[14] V.S. Praptowidodo, Influence of swelling on water transport through PVAbased membrane, J. Mol. Struct. 739 (2005) 207-212.

[15] W.Y. Chuang, T.H. Young, D.M. Wang, R.L. Luo, Y.M. Sun, Swelling behavior of hydrophobic polymers in water/ethanol mixtures, Polymer 41 (2000) 8339-8347. 